\title{
SEXUAL DIMORPHISM IN PERMANENT MAXILLARY AND MANDIBULAR CANINE OF MEDICAL STUDENTS IN GANDAKI MEDICAL COLLEGE, NEPAL
}

\author{
Shrestha $B$
}

\section{Affiliation}

1. Associate Professor, Oral Pathology, Gandaki Medical College, Nepal, Pokhara, Nepal

\section{ARTICLE INFO}

\section{Article History}

Received : 25 February, 2019

Accepted : 07 April, 2019

Published : 30 April, 2019

(C) Authors retain copyright and grant the journal right of first publication with the work simultaneously licensed under Creative Commons Attribution License CC - BY 4.0 that allows others to share the work with an acknowledgment of the work's authorship and initial publication in this journal.

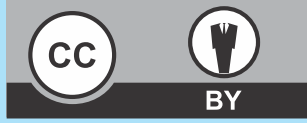

ORA 109

DOI: http://dx.doi.org/10.3126/bjhs.v4i1.23941

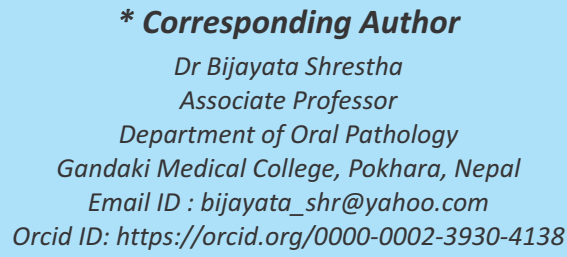

\section{Citation}

Shrestha B. Sexual dimorphism in Permanent Maxillary and Mandibular Canine of Medical students in Gandaki Medical College, Nepal. BJHS 2018;1(4)8: 654- 659.

\section{ABSTRACT}

\section{Introduction}

Gender determination is important for identification in forensic practice. Odontometrics plays an important role in sex determination in young individuals where secondary sexual characters are yet to be developed.

\section{Objective}

The objective was to re-evaluate the previous finding of the sexual dimorphism in Mesiodistal (MD) and Buccolingual $(\mathrm{BL})$ dimension of maxillary and mandibular canine in the study population being Medical Students of Medical College in province 4 of Nepal.

\section{Methodology}

This is a cross sectional study conducted on the study cast of 40 male and 40 female medical students of academic year 2017/18 of Gandaki Medical College, Nepal, of age group 18-24 from October to December 2017. The MD and BL dimensions of all the four canines were measured using digital vernier's caliper. Data were compared using descriptive statistics, student's t-test and paired sample $\mathrm{t}$ test. $\mathrm{P}<0.05$ was found statistically significant.

\section{Results}

Statistically significant sexual dimorphism was found in MD and $B L$ dimension of maxillary and mandibular canine with males' canine measuring larger than females'. The left mandibular canine was found to be the most dimorphic in term of $\mathrm{BL}$ dimension among the canines.

\section{Conclusion}

The present study exhibited the buccolingual dimension of the left mandibular canine as the most dimorphic tooth. Further studies using large representative sample from all the provinces has to be conducted to quantify and generalize the result among the Nepalese Dentition.

\section{KEYWORDS}

Human identification, permanent dentition, sexual dimorphism 


\section{INTRODUCTION}

Human identification is required in cases of fires, explosions, road traffic or aircraft accidents, mutilated or decomposed bodies. ${ }^{1}$ Sex determination is one of the important aspects of identification and assists forensic experts in the establishment of biological profile. ${ }^{2}$ As tooth is chemically the most stable tissue, resists extreme condition of post mortem changes, exhibit significant sexual dimorphism and is readily available for examination, it is considered to be a valuable and excellent tool for sex determination. ${ }^{3-5}$

The importance of tooth size measurement in the sex determination has been emphasized particularly in young individuals where secondary sexual characteristics have not developed. ${ }^{6}$ Previous studies related to sexual dimorphism in tooth size suggested that manidibular canine exhibits greatest sexual dimorphism. ${ }^{2,78}$ Mandibular canines are considered as the 'key teeth' for identification may be because they exhibit the greatest stability and are less susceptible for caries and periodontal diseases and most likely survive severe trauma. ${ }^{4,5}$

Acharya A.B. and Mainali S. noticed canine to be the most dimorphic teeth in Nepalese dentition and were significantly larger in males in both the mesiodistal (MD) and buccolingual (BL) dimensions. ${ }^{8}$ They noticed maxillary canine and $\mathrm{BL}$ dimension to be the most dimorphic. The study population used in the study were the undergraduate Dental students of Dental College in Province 1 of Nepal. In this study, we attempt to re-evaluate the dimorphism in the $\mathrm{MD}$ and $\mathrm{BL}$ dimension of all the permanent canines in the subset of Nepalese permanent Dentition, the study population being Medical Students of Medical College in province 4 of Nepal. Moreover, there is no recent study evaluating the sexual dimorphism of canine in Province number 4 Nepal.

\section{METHODOLOGY}

This cross sectional study was carried out on the medical students of Gandaki Medical College, Nepal from October to December 2017 after obtaining ethical approval from institutional ethical committee of Gandaki Medical College.

Sample size: A sample size was calculated with the reference of previous study on Nepalese population. ${ }^{8}$ The reference value for mean difference and standard deviation of buccolingual dimension of maxillary right canine was taken from previous study and the size was calculated using the formula: $n=2\left(Z_{\alpha / 2}+Z_{1-\beta}\right) 2 /(\mu 1-\mu 2 / \sigma) 2$ where $n$ is the number of subjects required in each group, $\mu 1-\mu 2$ denotes the difference of two means and $\sigma$ denotes the standard deviation with $\alpha=0.05, Z \alpha=1.96, \beta=0.2, Z \beta=0.84$ with statistical power chosen $80 \%{ }^{9}$ The calculated sample size was 23 for each gender.

Sampling: All the medical students of 1 st and 2 nd year of academic year 2017/18 in Gandaki Medical College (Female $=80$, Male-70) were invited to participate in this study. All the students were described about the study in detail and were informed about maintenance of the confidentiality and anonymity of the data. All the students were clinically examined with the use of diagnostic instrument. Out of all the students (Female $=80$ and Male= 70), the eligible students to be included in this study were 50 male and 55 female students. Out of the total eligible students, 40 Male and 40 Female students were selected using random sampling technique. The higher limit of sample size was selected to better represent the study population.

Inclusion and exclusion Criteria: Participants with healthy gingiva and periodontium, caries free teeth and normal occlusion (having normal canine and molar relationship) and of age groups 18-24 were included in the study.

Participants who were having any developmental anomaly, spacing, crown, bridge, restoration on canine, attrited or missing canine, orthodontic treatment or any history of trauma, were excluded from this study.

Procedure: After obtaining the informed consent, maxillary and mandibular impressions of all the selected participants were made using alginate material using perforated metal stock tray. The impression was washed with water, disinfected by $2 \%$ glutaraldehyde, and cast-pouring was done immediately with type III dental stone.

The greatest mesiodistal (MD) and buccolingual (BL) diameter of the maxillary (Figure 1a. and 1b.) and mandibular canine (Figure $2 \mathrm{a}$ and $2 \mathrm{~b}$.) were measured by a digital vernier caliper. All the measurements were carried out by the researcher using the digital vernier caliper of resolution $0.01 \mathrm{~mm}$. Intraobserver error was measured by using vernier caliper on 40 male and 40 female student's cast

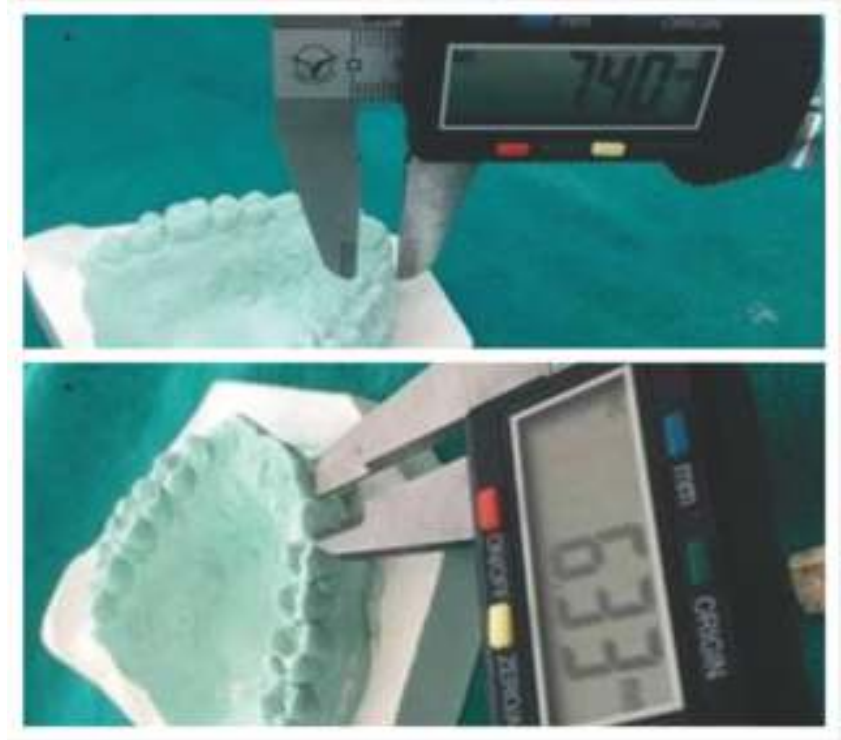

Figure 1a. and 1b: Shows greatest mesiodistal (MD) and buccolingual $(B L)$ diameter of the maxillary Canine measured by a digital vernier caliper

at a different time by same observer.

The mesiodistal (MD) measurement was defined as the greatest MD dimensions between contact points of teeth on either side of the jaw, and the buccolingual (BL) measurement was defined as the greatest distance between the labial and lingual surface of the crown taken at right angle to the MD 
dimension. Measurements were recorded on Microsoft excel and subjected to statistical analysis using Statistical Package for the Social Sciences (SPSS) version 20.0 USA, Echo soft Corp. software. The data was analyzed using descriptive statistics, student's t test and paired sample t test.

The mean value of $\mathrm{MD}$ and $\mathrm{BL}$ dimensions of male and female were used to calculate sexual dimorphism. Sexual dimorphisms in the right and left canines were calculated using the formula given by Garn and Lewis (1967): ${ }^{10}$

Percentage of sexual dimorphism $=[(\mathrm{Xm} / \mathrm{Xf})-1] \times 100$ where $\mathrm{Xm}=$ mean of male tooth dimension, $\mathrm{Xf}=$ mean of female

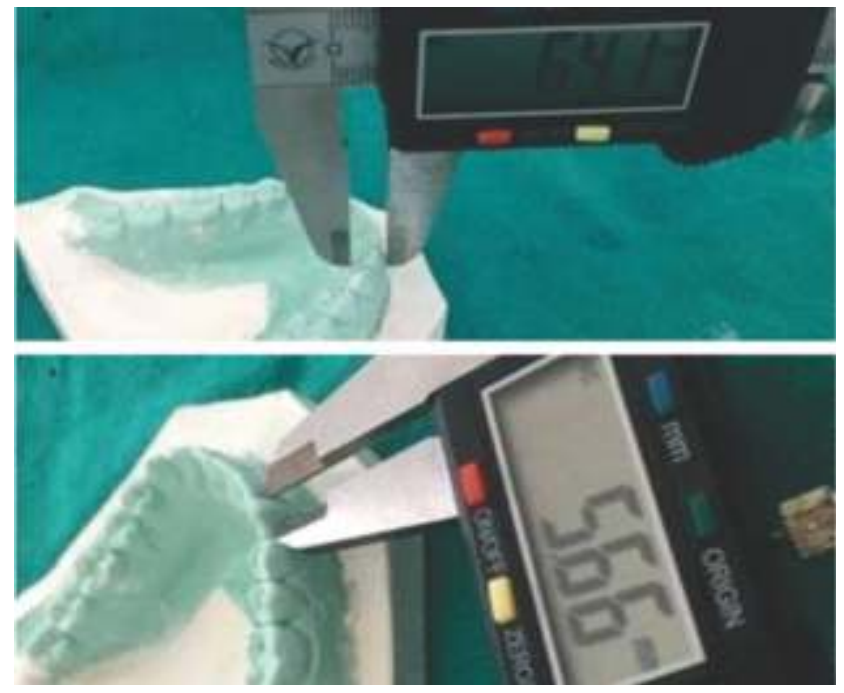

Figure $2 \mathrm{a}$ and $2 \mathrm{~b}$ : Shows greatest mesiodistal (MD) and buccolingual (BL) diameter of mandibular canine measured by a digital vernier caliper.

\section{RESULTS}

The following parameters were measured and compared on study cast for $M D$ and $B L$ dimensions for right and left maxillary and mandibular canine using student $t$ test and paired sample t test statistical analysis with data entered in Statistical Package for the Social Sciences (SPSS) 20 software.

Males showed greater mean $\mathrm{MD}$ and $\mathrm{BL}$ dimensions in comparision to females in both maxillary and mandibular canines. It was observed that the mean values of both the $M D$ and $B L$ diameters showed statistically significant difference between male and female with $P<0.05$ in the maxillary and mandibular canines (Table 1 and Table 2 ).

$\mathrm{BL}$ dimension was seen more than MD dimensions in both the maxillary and mandibular canines in both the gender(Table 3 and 4).

Among the maxillary canine, the left side was found to show more dimorphism 4.2\% in terms of MD dimension (Table 5).

Among the mandibular canine, the left side was found to exhibit more dimorphism $9.05 \%$ in terms of buccolingual dimension (Table 6).

According to statistical values, the mandibular canine showed more dimorphism in terms of BL dimensions when compared to maxillary canine (Table 7).
The $M D$ and $B L$ of the right and the left mandibular canine are significantly different with the left side larger than the right in males. In females only the MD dimension of the right and the left maxillary canine is significantly different with the right side slightly larger than the left (Table 8).

Table 1: Descriptive statistics and student's t test for comparing the mean value of the mesiodistal (MD) width of maxillary and mandibular canine in the male and the female. Level of significance set as $\mathrm{P}<0.05$

$\begin{array}{llrrccc} & \text { Gender } & \text { N } & \begin{array}{c}\text { MD } \\ \text { Mean }\end{array} & \begin{array}{c}\text { Standard } \\ \text { Deviation }\end{array} & \text { T value } & \text { P value } \\ \text { MD13 } & \text { Male } & 40 & 7.92 & 0.453 & 2.66 & 0.01 \\ & \text { Female } & 40 & 7.67 & 0.445 & & \\ \text { MD23 } & \text { Male } & 40 & 7.87 & 0.473 & 3.068 & 0.004 \\ & \text { Female } & 40 & 7.55 & 0.482 & & \\ \text { MD33 } & \text { Male } & 40 & 7.19 & 0.466 & 4.6 & 0.000 \\ & \text { Female } & 40 & 6.7 & 0.457 & & \\ \text { MD43 } & \text { Male } & 40 & 7.037 & 0.467 & 3.7 & 0.001 \\ & \text { Female } & 40 & 6.64 & 0.534 & & \end{array}$

Table 2: Descriptive statistics and student's t test for comparing the mean value of the buccolingual (BL) width of maxillary and mandibular canine in the male and the female. Level of significance set as $\mathrm{P}<0.05$

$\begin{array}{lcccccc} & \text { Gender } & \text { N } & \begin{array}{c}\text { BL } \\ \text { Mean }\end{array} & \begin{array}{c}\text { Standard } \\ \text { Deviation }\end{array} & \text { t value } & \text { P value } \\ \text { BL13 } & \text { Male } & 40 & 8.439 & 0.525 & 2.25 & 0.03 \\ & \text { Female } & 40 & 8.13 & 0.609 & & \\ \text { BL23 } & \text { Male } & 40 & 8.426 & 0.568 & 2.35 & 0.024 \\ & \text { Female } & 40 & 8.11 & 0.592 & & \\ \text { BL33 } & \text { Male } & 40 & 8.076 & 0.4595 & 6.676 & 0.000 \\ & \text { Female } & 40 & 7.41 & 0.492 & & \\ \text { BL43 } & \text { Male } & 40 & 7.926 & 0.475 & 4.793 & 0.000 \\ & \text { Female } & 40 & 7.368 & 0.577 & & \end{array}$

Table 3: Descriptive statistics and paired sample $t$ test for comparing the mean value of mesiodistal (MD) and buccolingual (BL) dimension of maxillary and mandibular canines in the male. Level of significance at the level of $\mathrm{P}<0.05$.

\begin{tabular}{ccccccc} 
Canine & Dimension & N & Mean & $\begin{array}{c}\text { Standard } \\
\text { Deviation }\end{array}$ & $\begin{array}{c}\text { Paired } \\
\text { Sample } \\
\text { T-Test }\end{array}$ & P value \\
\hline 13 & MD & 40 & 7.67 & 0.445 & 6.594 & $\mathrm{P}<0.001$ \\
& $\mathrm{BL}$ & 40 & 8.13 & 0.609 & & \\
23 & $\mathrm{MD}$ & 40 & 7.55 & 0.482 & 7.889 & $\mathrm{P}<0.001$ \\
& $\mathrm{BL}$ & 40 & 8.11 & 0.609 & & \\
33 & $\mathrm{MD}$ & 40 & 6.7 & 0.457 & 11.547 & $\mathrm{P}<0.001$ \\
& $\mathrm{BL}$ & 40 & 7.41 & 0.492 & & \\
43 & $\mathrm{MD}$ & 40 & 6.64 & 0.543 & 8.823 & $\mathrm{P}<0.001$ \\
& $\mathrm{BL}$ & 40 & 7.37 & 0.577 & & \\
& & & & & &
\end{tabular}

Table 4: Descriptive statistics and paired sample t test for comparing the mean value of mesiodistal (MD) and buccolingual (BL) dimension of maxillary and mandibular canines in the female. Level of significance at the level of $\mathrm{P}<0.05$.

\begin{tabular}{cccccccc} 
Canine Dimension & N & Mean & $\begin{array}{c}\text { Standard } \\
\text { Deviation }\end{array}$ & T value & P value \\
\hline 13 & MD & 40 & 7.9245 & 0.453 & 8.502 & 0.000 \\
& BL & 40 & 8.4397 & 0.525 & & \\
23 & MD & 40 & 7.87 & 0.473 & 9.432 & 0.000 \\
& BL & 40 & 8.43 & 0.568 & & \\
43 & MD & 40 & 7.19 & 0.466 & 15.117 & 0.000 \\
& BL & 40 & 8.07 & 0.4595 & & \\
& MD & 40 & 7.037 & 0.467 & 12.56 & 0.000 \\
& BL & 40 & 7.93 & 0.475 & & \\
& & & & & & &
\end{tabular}


Table 5: Descriptive statistics and Sexual dimorphism (\%) used for comparing the mean value of mesiodistal (MD) and buccolingual (BL) dimensions of right and left maxillary canines in male and female. SD-Standard deviation

\begin{tabular}{lcccccccc}
\multicolumn{1}{c}{ Gender(N) } & \multicolumn{4}{c}{ Right side } & \multicolumn{4}{c}{ Left side } \\
& MD & SD & BL & SD & MD & SD & BL & SD \\
Males(40) & 7.92 & 0.453 & 8.44 & 0.525 & 7.87 & 0.473 & 8.43 & 0.525 \\
Females(40) & 7.67 & 0.445 & 8.1 & 0.609 & 7.55 & 0.482 & 8.1 & 0.592 \\
Sexual & \multirow{2}{*}{3.2} & & 4.1 & & 4.2 & & 4.07
\end{tabular}

Table 6: Descriptive statistics and Sexual dimorphism (\%) used to compare the mean value of mesiodistal (MD) and buccolingual $(\mathrm{BL})$ dimensions of right and left maxillary canines in male and female. SD-Standard deviation

\begin{tabular}{lcccccccc} 
& \multicolumn{4}{c}{ Right side } & \multicolumn{4}{c}{ Left side } \\
\multicolumn{1}{c}{ Gender(N) } & MD & SD & BL & SD & MD & SD & BL & SD \\
Males(40) & 7.037 & 0.467 & 7.93 & 0.475 & 7.19 & 0.466 & 8.07 & 0.4595 \\
Females(40) & 6.64 & 0.534 & 7.3 & 0.577 & 6.7 & 0.457 & 7.4 & 0.492 \\
Sexual & & 6 & & 8.6 & & 7.3 & & 9.05 \\
dimorphism (\%) & & & & & & & &
\end{tabular}

Table 7: Garn's ratio and sexual dimorphism in maxillary and mandibular canines. MD-Mesiodistal,BL-Buccolingual, SD-standard deviation

\begin{tabular}{llllllllll} 
Gender (N) & \multicolumn{4}{c}{ Maxillary Canine width (mm) } & \multicolumn{4}{c}{$\begin{array}{c}\text { Mandibular Canine width } \\
(\mathbf{m m})\end{array}$} \\
& MD & SD & BL & SD & MD & SD & BL & SD \\
Male (40) & 7.90 & 0.463 & 8.44 & 0.5465 & 7.11 & 0.466 & 8.0 & 0.467 \\
Female (40) & 7.61 & 0.4634 & 8.1 & 0.609 & 6.67 & 0.5 & 7.35 & 0.535 \\
Garn's ratio & 3.8 & & 4.2 & & 6.6 & & 8.84 &
\end{tabular}

Table 8: Descriptive statistics and paired sample t test to compare the mean dimensions of buccolingual (BL) and mesiodistal (MD) width of the right and left sided maxillary and mandibular canines in male and female. Level of significance at level of $P<0.05$

\begin{tabular}{|c|c|c|c|c|c|c|c|}
\hline Gender & Tooth Dimension & Side & $\mathbf{N}$ & Mean & $\begin{array}{l}\text { Standard } \\
\text { Deviation }\end{array}$ & t value & P value \\
\hline \multirow[t]{8}{*}{ Male } & \multirow[t]{2}{*}{ Maxillary BL } & Right & 40 & 8.44 & 0.525 & \multirow[t]{2}{*}{0.213} & \\
\hline & & Left & 40 & 8.43 & 0.68 & & 0.833 \\
\hline & \multirow[t]{2}{*}{ Maxillary MD } & Right & 40 & 7.92 & 0.453 & \multirow[t]{2}{*}{0.825} & \multirow[t]{2}{*}{0.414} \\
\hline & & Left & 40 & 7.87 & 0.473 & & \\
\hline & \multirow[t]{2}{*}{ Mandibular BL } & Right & 40 & 7.93 & 0.475 & \multirow[t]{2}{*}{3.17} & \multirow[t]{2}{*}{0.003} \\
\hline & & Left & 40 & 8.08 & 0.4595 & & \\
\hline & \multirow[t]{2}{*}{ Mandibular MD } & Right & 40 & 7.04 & 0.467 & \multirow[t]{2}{*}{2.75} & \multirow[t]{2}{*}{0.009} \\
\hline & & Left & 40 & 7.2 & 0.466 & & \\
\hline \multirow[t]{8}{*}{ Female } & \multirow[t]{2}{*}{ Maxillary BL } & Right & 40 & 8.13 & 0.609 & \multirow[t]{2}{*}{0.33} & \multirow[t]{2}{*}{0.74} \\
\hline & & Left & 40 & 8.11 & 0.592 & & \\
\hline & \multirow[t]{2}{*}{ Maxillary MD } & Right & 40 & 7.67 & 0.445 & \multirow[t]{2}{*}{2.21} & \multirow[t]{2}{*}{0.03} \\
\hline & & Left & 40 & 7.55 & 0.482 & & \\
\hline & \multirow[t]{2}{*}{ Mandibular BL } & Right & 40 & 7.37 & 0.577 & \multirow[t]{2}{*}{0.69} & \multirow[t]{2}{*}{0.429} \\
\hline & & Left & 40 & 7.41 & 0.492 & & \\
\hline & \multirow[t]{2}{*}{ Mandibular MD } & Right & 40 & 7.04 & 0.467 & \multirow[t]{2}{*}{1.04} & \multirow[t]{2}{*}{0.303} \\
\hline & & Left & 40 & 7.2 & 0.466 & & \\
\hline
\end{tabular}

\section{DISCUSSION}

Among all the teeth, canine has been noticed as the most dimorphic tooth, and males exhibited larger tooth in Nepalese dentition. ${ }^{8}$ Our study was limited to the measurement of $\mathrm{MD}$ and $\mathrm{BL}$ dimensions of maxillary and mandibular canines. We observed statistically significant differences in the MD and BL dimensions of both maxillary and mandibular canines. We observed greater $\mathrm{MD}$ and $\mathrm{BL}$ dimensions of canines in males as was seen in other studies. ${ }^{6,8}$ In a study by Davoudmanesh et al. mean MD dimensions were shown to be greater in males in terms of all canines, and the $\mathrm{BL}$ dimension were greater in men only in terms of maxillary canine and not the mandibular canine. ${ }^{11}$
The sexual dimorphism in canine can be explained based on its functional role in survival, especially in males. It had been postulated that the canines were functionally related to threats of aggression in primates and with the evolutionary change had been shifted to fingers in human suggesting sexual dimorphism in canine is not just a coinincidental findings but is expected. ${ }^{12}$

However, Baoz and Gupta and Shreedhar G et al. found reverse sexual dimorphism. ${ }^{13,4}$ Boaz and Gupta observed that the mean value of $\mathrm{BL}$ and $\mathrm{MD}$ dimension of mandibular canine is greater in females, but the difference was not statistically significant. ${ }^{13}$ Shastry et al. found mean maxillary canine width in females slightly more than males, but the difference was not statistically significant. ${ }^{14}$ Shreedhar $\mathrm{G}$ et al. found statistically significant reverse sexual dimorphism in mandibular canine. ${ }^{4}$ These findings were attributed to evolutionary change which resulted in the overlap of tooth dimension and reduction in sexual dimorphism in a modern human.

The mean value of $\mathrm{BL}$ dimension was found to be more than MD dimension of canine in both males and females as seen in studies by Acharya and Mainali, Boaz and Gupta and in Wheeler. ${ }^{8,13,15}$ In contrast to our finding Agrawal A et al. found that the mean value of $\mathrm{MD}$ dimensions was larger than $\mathrm{BL}$ dimensions. ${ }^{16}$

The "Key Tooth" for sex determination is the mandibular canine. This may be because mandibular canines are the most stable tooth being less susceptible to periodontal disease and caries and most likely survive severe trauma. ${ }^{4,5}$

In this study, mandibular canine exhibited greater sexual dimorphism than maxillary canine which was in accordance with work done by previous studies. ${ }^{7,13,17}$ However, the findings of studies by Acharya and Mainali, Pandey $\mathrm{N}$ et al. were not consistent with our finding. ${ }^{8,6}$ They found maxillary canine exhibited greater dimorphism. Our finding was not consistent with similar study in Nepalese dentition. ${ }^{8}$ This discrepancy may be due to the fact that these two studies were conducted in different environmental set up and the previous study which included dental undergraduate students in different province was not representative of entire Nepalese population.

Hasim and Mursid found that there was no statistically significant difference between the dimension of the right and left side teeth suggesting that availability of measurement on one side is enough for the sex determination. ${ }^{18}$ Whereas we found a significant difference in terms of the MD and BL dimension of the right and left mandibular canine in males whereas females showed a significant difference in the MD measurement of the right and left maxillary canine. Our finding suggested that one side of teeth is not representative in case of mandibular canines in males and MD dimension of maxillary canine in females.

Our findings confirmed the previous findings that the left mandibular canine showed greater sexual dimorphism than the right canine. ${ }^{7,12}$ In contrast to our findings, Viswokarma 
and Guha and Ch. Shai Kiran et al. reported greater dimorphism in the right mandibular canine compared to the left canine. ${ }^{5,19}$

The present study confirmed the previous finding in Nepalese Dentition that a significant sexual dimorphism exists in the MD and BL dimension of the maxillary as well as the mandibular canine. Among the four canines, the left mandibular canine was found to be the most dimorphic in term of BL dimension among the canines among the study samples.

\section{CONCLUSION}

This study confirms the existence of statistically significant differences in canine between males and females. The left mandibular canine in terms of buccolingual dimension was observed as the most dimorphic tooth among the canines. Further study including larger representative sample of Nepalese population from various provinces has to be conducted to quantify and generalize the result among Nepalese dentition.

\section{RECOMMENDATION}

Canine has been seen to have significant role in gender determination and thus in identification in forensic practice. It is highly recommended to conduct similar study including large population to see the sexual dimorphism of canine in Nepalese population.

\section{REFERENCES}

1. Hosmani J V, Nayak RS, Kotrashetti V S, Pradeep S, Babji D. Reliability of Mandibular Canines as Indicators for Sexual Dichotomy. J Int Oral Health. 2013 Feb; 5(1):1-7. PMID 24155571.

2. V N, Ugrappa S, M NJ, Ch L, Maloth KN, Kodangal S. Cheiloscopy, Palatoscopy and Odontometrics in Sex Prediction and Discrimination - a Comparative Study. The Open Dentistry Journal. 2014 Jan; 8:269-279. DOI: 10.2174/1874210601408010269.

3. Yuwanati M, Karia A, Yuwanati M. Canine tooth dimorphism: An adjunct for establishing sex identity. Journal of Forensic Dental Sciences. 2012 Jul-Dec; 4(2):80-83. DOI: 10.4103/0975-1475. 109892.

4. Sreedhar G, Sumalatha MN, Ramesh G, Nagarajappa R, Murari A, Agrawal A. Dimorphic Mandibular canines in gender determination in Moradabad population of Western Uttar Pradesh. Journal of Forensic Dental Sciences. 2015 Jan-Apr; 7(1):32-36. DOI: 10.4103/09751475.150302.

5. Vishwakarma N, Guha R. A study of sexual dimorphism in permanent mandibular canines and its implications in forensic investigations. Nepal Med Coll J. 2011 Jun; 13(2):96-99. PMID: 22364090.

6. Pandey N, Ma MS. Evaluation of sexual dimorphism in maxillary and mandibular canine using mesiodistal, labiolingual dimensions, and crown height. Indian Journal of dental research. 2016 Sept-Oct; 27(5):473-476. DOI: 10.4103/0970-9290.195616.

7. Hashim HA, Murshid ZA. Mesiodistal tooth width. A comparison between Saudi males and females. Part 1. Egypt Dent J. 1993 Jan; 39(1):343-346. PMID: 8299532.

\section{LIMITATION OF STUDY}

This study includes the evaluation of maxillary and mandibular canine of only the medical undergraduates of $1^{\text {st }}$ and $2^{\text {nd }}$ year. We could have generalized the result in Nepalese population if we had large sample size including more individuals with various ethnic backgrounds representing Nepalese population and possibly representation from all the provinces of Nepal.

\section{ACKNOWLEDGEMENT}

I would like to express my deep gratitude to Dr Ishowri Sharma, Professor in the department of Community Medicine, Gandaki Medical College for carrying out the statistical analysis and Dr Sushil Subedi in supporting me during this research study. I would like to thank all the MBBS $1^{\text {st }}$ and 2 nd year students of academic year $2017 / 18$ for their participation in this study.

\section{CONFLICT OF INTEREST}

None

\section{FINANCIAL DECLARATION}

None

8. Acharya A, Mainali S. Univariate sex dimorphism in the Nepalese dentition and the use of discriminant functions in gender assessment. Forensic Sci Int. 2007 Nov; 173:47-56. DOI: 10.1016/ j.forsciint.2007.01.024.

9. Allen JC Jr. Sample Size Calculation for Two Independent Groups: A Useful Rule of Thumb. Proceedings of Singapore Healthcare. 2011;2(20):138-140. Available from https://journals.sagepub.com/ doi/pdf/10.1177/201010581102000213

10. Garn SM, Lewis AB, Swindler DR, Kerewsky RS. Genetic control of sexual dimorphism in tooth size. J Dent Res.1967 Sept-Oct; 46(5):963-972. DOI: 10.1177/00220345670460055801.

11. Davoudmanesh Z, Shariat M, Azizi1 N, Yekaninejad S, Hozhabr H, Kadkhodaei-Oliadarani F. Sexual dimorphism in permanent canine teeth and formulas for sex determination. Biomed Res India. 2017; 28:2773-2777. Available from http://www.biomedres.info/ biomedical-research/sexual-dimorphism-in-permanent-canineteeth-and-formulas-for-sex-determination.html.

12. Kaushal S, Patnaik VV, Agnihotri G. Mandibular canine in sex determination. J Anat Soc India. 2003; 52:119-124. Available at http://medind.nic.in/jae/t03/i2/jaet03i2p119.pdf.

13. Boaz K, Gupta C. Dimorphism in human maxillary and mandibular canines in establishment of gender. J Forensic Dental Sciences. 2009; 1(1):42-44. DOI: 10.4103/0974-2948.50889. 
14. Shastry SP, Padmashree S, Kaul R, Rema J, Pandeshwar P, Mahesh B. Sexual dimorphism using canine width and inter-canine distance in South Indian population: A cross sectional study. Ann Int Med Dent Res. 2016; 2:258-263. Available from http://aimdrjournal.com/ pdf/Vol2Issue1_660A.pdf.

15. Ash NM, Nelson SJ. Wheeler's Dental Anatomy, Physiology and Occlusion 8th Ed, Philadelphia: W.B.Saunder's Company; 2009. p. 201-202.

16. Agrawal A, Manjunatha BS, Dholia B, Althomali Y. Comparison of sexual dimorphism of permanent mandibular canine with mandibular first molar by odontometrics. Journal of Forensic Dental Sciences. 2015 sept-Dec; 7(3):238-243. DOI: 10.4103/09751475.172449 .
17. Pramod RC, Nupura V, Suresh KV, Vidya K, Sharan JS, Neha S. Role of maxillary and mandibular canine indices in sex determination: Perspective of a forensic odontologist. CODS J Dent. 2014; 6:68-71. Available from https://www.researchgate.net/ publication/ 280022193.

18. Hashim HA, Murshid ZA. Mesiodistal tooth width in a Saudi population sample comparing right and left sides. Part 2. Egypt Dent J. 1993; 39(1):347-350. PMID: 8299532.

19. Ch. Sai kiran, Tanya Khaitan, P. Ramaswamy, S. Sudhakar, B. Smitha, G. Uday. Role of mandibular canines in establishment of gender. Egyptian Journal of Forensic Sciences. 2014 Sept; 4(3): 71-74. Available from https://doi.org/10.1016/j.ejfs.2014.05.003. 